\title{
THE
}

\section{Westward-propagating SST Anomaly Features in the Sargasso Sea, 1982-88}

George R. Halliwell Jr.

University of Rhode Island

Peter C. Cornillon

University of Rhode Island, pcornillon@uri.edu

Deidre A. Byrne

University of Rhode Island

Follow this and additional works at: https://digitalcommons.uri.edu/gsofacpubs

\section{Citation/Publisher Attribution}

Halliwell, G. R., Cornillon, P. C., \& Byrne, D. A. (1991). Westward-propagating SST Anomaly Features in the Sargasso Sea, 1982-88. J. Phys. Oceanogr., 21, 635-649. doi: 10.1175/1520-0485(1991)0212.0.C0;2. Available at: https://doi.org/10.1175/1520-0485(1991)021<0635:WPSAFI>2.0.C0;2

This Article is brought to you for free and open access by the Graduate School of Oceanography at DigitalCommons@URI. It has been accepted for inclusion in Graduate School of Oceanography Faculty Publications by an authorized administrator of DigitalCommons@URI. For more information, please contact digitalcommons-group@uri.edu. 


\title{
Westward-propagating SST Anomaly Features in the Sargasso Sea, 1982-88
}

\author{
George R. Halliwell, JR.* and Peter CoRnillon \\ Graduate School of Oceanography, University of Rhode Island, Narragansett, Rhode Island \\ DEIRDRE A. BYRNE \\ Lamont-Doherty Geological Observatory, Columbia University, Palisades, New York
}

(Manuscript received 8 February 1990, in final form 11 October 1990)

\begin{abstract}
Sea surface temperature $\left(T_{s}\right)$ maps of the region from $59.5^{\circ}$ to $75.5^{\circ} \mathrm{W}, 22.5^{\circ}$ to $33.5^{\circ} \mathrm{N}$ containing the western North Atlantic Subtropical Convergence Zone (STCZ) were derived from AVHRR/2 images. The 7year mean annual cycle was removed and the maps were filtered in space and time to represent anomaly variability with wavelengths $\geqslant 220 \mathrm{~km}$ and periods $\geqslant 50$ days. Warm and cold anomaly features were observed east of $71^{\circ} \mathrm{W}$ between $26^{\circ}$ and $32^{\circ} \mathrm{N}$ that propagated westward at $3-4 \mathrm{~km}^{-1} \mathrm{y}^{-1}$ and that occasionally exceeded $\pm 1^{\circ} \mathrm{C}$ in amplitude. They are generally strong and persistent from fall to spring, and are only marginally detectable during summer. During 1981-82, 1982-83, and 1985-86, individual features could be followed through the entire fall-spring interval. During 1983-84, 1986-87, and 1987-88, they could typically be followed for 2-4 months, and during 1984-85, for only 1-2 months. The features were anisotropic during all fall-spring intervals except 1986-87, and they had characteristic wavelengths of $\sim 800 \mathrm{~km}$ in the minor axis direction and periods of $\sim 200$ days. Local forcing by synoptic atmospheric variability alone could not account for the existence of these features. Anomaly features propagated westward in a manner consistent with theoretical zonal dispersion properties of first-mode baroclinic Rossby waves, suggesting that the anomalies may be coupled to a field of wavelike eddies. Since the anomalies were confined to the zonal band of large mean meridional $T_{s}$ gradients associated with the STCZ, where meridional eddy currents are relatively effective at forcing anomalies these eddy currents could be largely responsible for their existence. In one case, however, the influence of eddies on vertical heat flux at the mixed layer base appeared to be important. The relatively strong and persistent 198586 anomaly features appeared during a several-day interval at the onset of relatively stormy fall weather and (presumably) rapid mixed-layer deepening.
\end{abstract}

\section{Introduction}

The Frontal Air-Sea Interaction Experiment (FASINEX) was designed to study air-sea interaction in the vicinity of a strong oceanic front (Stage and Weller $1985,1986)$. The subtropical front within the Sargasso Sea Subtropical Convergence Zone (STCZ), which is the latitude band separating the westerlies to the north from the trade winds to the south, was selected for this study because it is relatively strong and persistent during winter (e.g., Voorhis 1969). The meridional convergence of wind-driven Ekman transport within the STCZ is considered to be an important mechanism for generating subtropical fronts (e.g., Roden 1975).

Studies of the large-scale background sea-surface temperature $\left(T_{s}\right)$ variability during FASINEX (Jan-

\footnotetext{
* Present affiliation: MPO/RSMAS, University of Miami.
}

Corresponding author address: Dr. George R. Halliwell, Jr., Rosenstiel School of Marine and Atmos. Science, Div. of Meteor. and Phys. Oceanography, 4600 Rickenbacker Causeway, Miami, FL 33149-1098.
uary-June 1986) revealed the existence of strong (extrema exceeding $\pm 1^{\circ} \mathrm{C}$ ), anisotropic, and persistent (lasting for $>4$ months) large-scale anomaly features within the Sargasso Sea STCZ that propagated westward at $\sim 3 \mathrm{~km} \mathrm{day}^{-1}$ (Halliwell and Cornillon 1989). Their major axis was oriented SW-NE, and they had characteristic peak-to-peak scales of about $800 \mathrm{~km}$ (minor axis direction) and 275 days. The westward propagation of these features dominated $T_{s}$ variability after removing the seasonal cycle and thus masked the influence of wind-driven Ekman transport on $T_{s}$ and subtropical fronts (Halliwell and Cornillon 1990b). Instead, the large-scale distribution and strength of fronts in the Sargasso Sea is more clearly related to the location and strength of the $T_{s}$ anomaly features than to the wind field (Halliwell and Cornillon 1989; Halliwell and Cornillon 1990b). Evidence presented in these studies and in Halliwell (1990) suggests that the influence of the underlying baroclinic eddy field on the mixed layer could be responsible for the existence of the anomaly features.

Because of the large space and time scales of the anomaly features, only a rough determination of their 
properties was possible during the six-month FASINEX interval. The primary goals of the present study are to more accurately characterize the properties of these features, to document the spatial and temporal variability of these properties, to determine how typical the features observed during FASINEX are, and to gain further insight into the physical processes responsible for their existence. The creation of the seven-year $T_{s}$ dataset is described first, then the anomaly heat balance for a slab mixed layer is briefly described. A simplified version of this model is used to demonstrate that local atmospheric forcing alone cannot account for the existence of the propagating anomaly features. It is then demonstrated that the baroclinic eddy field is likely responsible for the existence of the features by statistically determining properties of the features and relating them to properties expected if the features are eddy-forced. Finally, a set of analyses are presented to give further insight into how the eddy field may be forcing the observed propagating anomaly features.

\section{Creation of the $T_{s}$ maps}

Maps of $T_{s}$ were created at five-day intervals between 4 January 1982 and 28 December 1988, where all dates represent the central day of a five-day interval. The analysis domain spans the region from $22.5^{\circ}$ to $33.5^{\circ} \mathrm{N}, 75.5^{\circ}$ to $59.5^{\circ} \mathrm{W}$ (Fig. 1), which completely contains and extends the $10^{\circ}$ latitude by $11^{\circ}$ longitude domain used for the FASINEX analyses (Halliwell and Cornillon 1990a). We had intended to extend the domain eastward to near $50^{\circ} \mathrm{W}$, but found that $T_{s}$ estimates east of $59^{\circ} \mathrm{W}$ were unreliable due to extensive cloud cover and reduced satellite coverage. Several improvements were made to the original method used to create the FASINEX $T_{s}$ maps (Halliwell and Cornillon

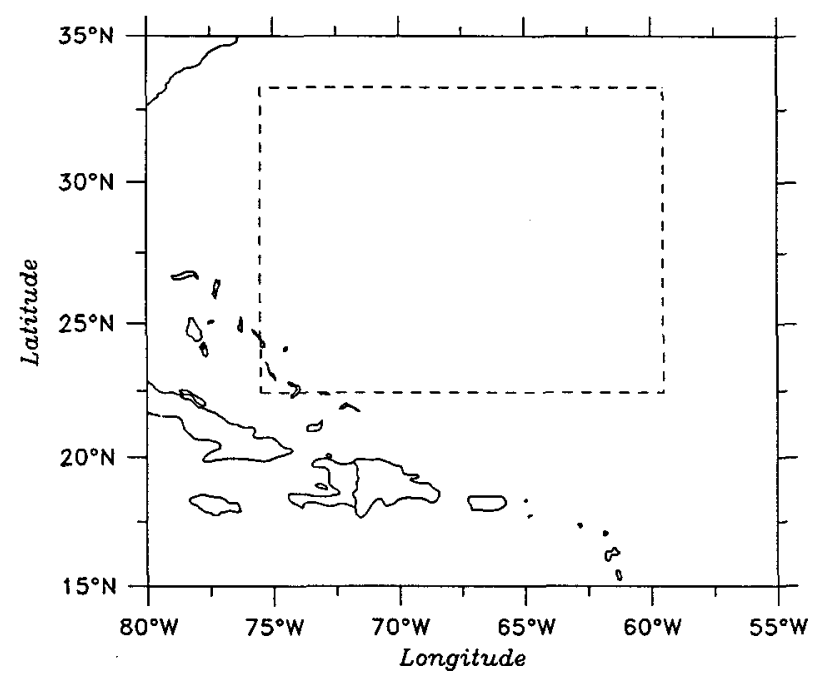

Analysis Domain

FIG. 1. The analysis domain (dashed box), bounded by $22.5^{\circ}$ and $33.5^{\circ} \mathrm{N}, 75.5^{\circ}$ and $59.5^{\circ} \mathrm{W}$. 1990a) based on what was learned from analyzing them. AVHRR / 2 images from NOAA-7, NOAA-9 and NOAA-11 satellites with a spatial resolution of about $4 \mathrm{~km}$ were processed to create the maps. Night images alone were used, which reduced the $0.5^{\circ}-0.6^{\circ} \mathrm{C}$ positive bias present in the FASINEX maps (Halliwell and Cornillon 1990a) by more than half. Five-day composite images were generated, and clouds were flagged, using the procedures developed for FASINEX (Halliwell and Cornillon 1990a).

The binning and averaging procedure used to create the FASINEX maps (Halliwell and Cornillon 1990a) was not used here. To generate the new set of maps, reduced-resolution images were first created by defining new pixels that span non-overlapping boxes of $5 \times 5$ original pixels, then using the median temperature in each box to represent $T_{s}$ in that reduced-resolution pixel. If no $T_{s}$ values were available in a box, then the reduced-resolution pixel was flagged as cloud contaminated. This reduction of resolution eliminated residual cloud contamination effects and improved computational efficiency. Between $2 \%$ and $85 \%$ of the reducedresolution pixels in the images were cloud contaminated, with an average of about one-third. Also, 28 of the 511 five-day intervals had no data at all because no input images were available. Three-dimensional objective analysis was used to fill the data gaps in the reduced-resolution images because this procedure minimizes the mean-square error of the interpolated temperatures. The three-dimensional autocorrelation function (Fig. 2) used for the objective analysis was calculated directly from the reduced-resolution images.

For each reduced-resolution pixel that did not have a $T_{s}$ estimate, an interpolated value was calculated using the objective analysis procedure described in Carter and Robinson (1987). For each interpolation, an expanding three-dimensional box was used to select input data values. Input image arrays were first searched within \pm 1 spatial grid point (about $\pm 20 \mathrm{~km}$ ) in both $x$ and $y$ and within \pm 1 map ( \pm 5 days) in time for at least 10 input data values. If fewer than 10 values were found, then the box was alternately expanded by \pm 1 point, first in both space dimensions and then in time. The number of box expansions was limited because the correlation between input data values and variability at the interpolation point becomes insignificant when they become too far removed in space and time. More than one input data value was always found by this search procedure. Since more than ten data values were usually found, the ten that had the largest values of a correlation index were selected to perform the interpolation. For a given input data value, this index equals the correlation between the input data value and the interpolation point minus the average correlation between the input data value and all of the other input data. These correlations were estimated using the three-dimensional autocorrelation function in Fig. 


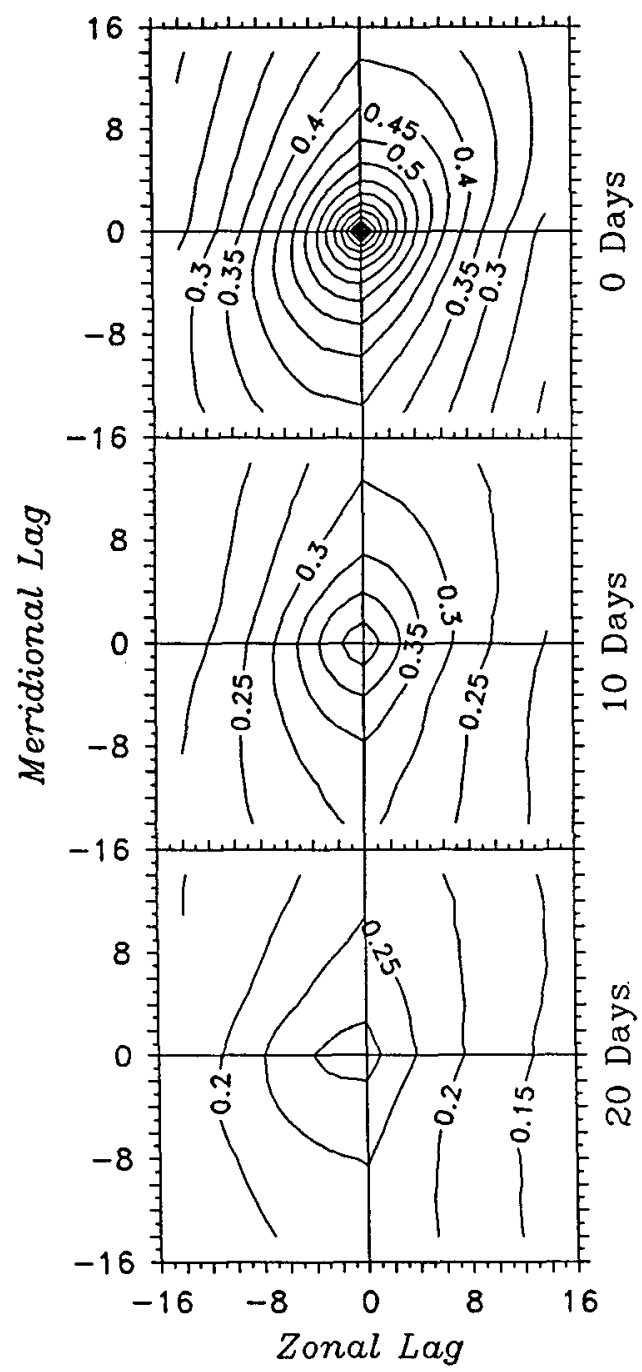

FIG. 2. Three-dimensional autocorrelation function of $T_{s}$ used in the objective analysis. The function is contoured as a function of zonal and meridional lag in degrees at 0,10 , and 20 day lag times.

2. This index tends to select input data values that are highly correlated with the interpolation point and tends to reject input data values that are highly correlated with (not statistically independent of) the other input data. Previously interpolated values were never used as input data.

The effective space-time resolution of $T_{s}$ in the gapfilled five-day maps was relatively high for regions in the space-time domain where few $T_{s}$ estimates were missing and relatively low for regions where large gaps existed. A two-dimensional Shapiro filter (Shapiro 1970) was thus used to spatially smooth the $T_{s}$ maps and make the effective spatial resolution roughly the same at all locations and times. The Shapiro filter was chosen because of its capability to suppress boundary effects. Filter parameters were chosen so that $T_{s}$ features the size of the energetic mesoscale eddies observed in this region (e.g., Richman et al. 1977) could still be resolved. It produced a gain of 0.1 at a wavelength of $\sim 165 \mathrm{~km}, 0.5$ at $\sim 220 \mathrm{~km}$, and 0.8 at $\sim 290 \mathrm{~km}$ (Fig. 3 ). For the present analyses, this set of $T_{s}$ maps was interpolated onto a grid with $0.5^{\circ}$ resolution in both latitude and longitude using bicubic splines since higher resolution was not required. The central point of this grid is located at $28^{\circ} \mathrm{N}, 67.5^{\circ} \mathrm{W}$. The resulting data set analyzed here consists of 511 five-day $T_{s}$ maps, each on a $33 \times 23$ point spatial grid spanning the region $22.5^{\circ}$ to $33.5^{\circ} \mathrm{N}, 75.5^{\circ}$ to $59.5^{\circ} \mathrm{W}$. A one-dimensional Shapiro filter was then used to low-pass these time series of $T_{s}$ at each grid point. Filter parameters were chosen so that the energetic 100-day period fluctuations associated with the mesoscale eddies could still be resolved. It produced a gain of 0.1 at a period of $\sim 35$ days, 0.5 at $\sim 50$ days, and 0.8 at $\sim 67$ days (Fig. 3 ).

To analyze large-scale $T_{s}$ anomaly features, the seven-year average annual cycle was calculated at each grid point and removed to create temporal anomaly $\left(T_{s a}\right)$ maps. For all analyses designed to estimate properties of the westward-propagating anomaly features, we used a set of $T_{s a}^{\prime}$ maps calculated by removing the means and two-dimensional linear trends from the $T_{s a}$ maps using a least-squares fit.

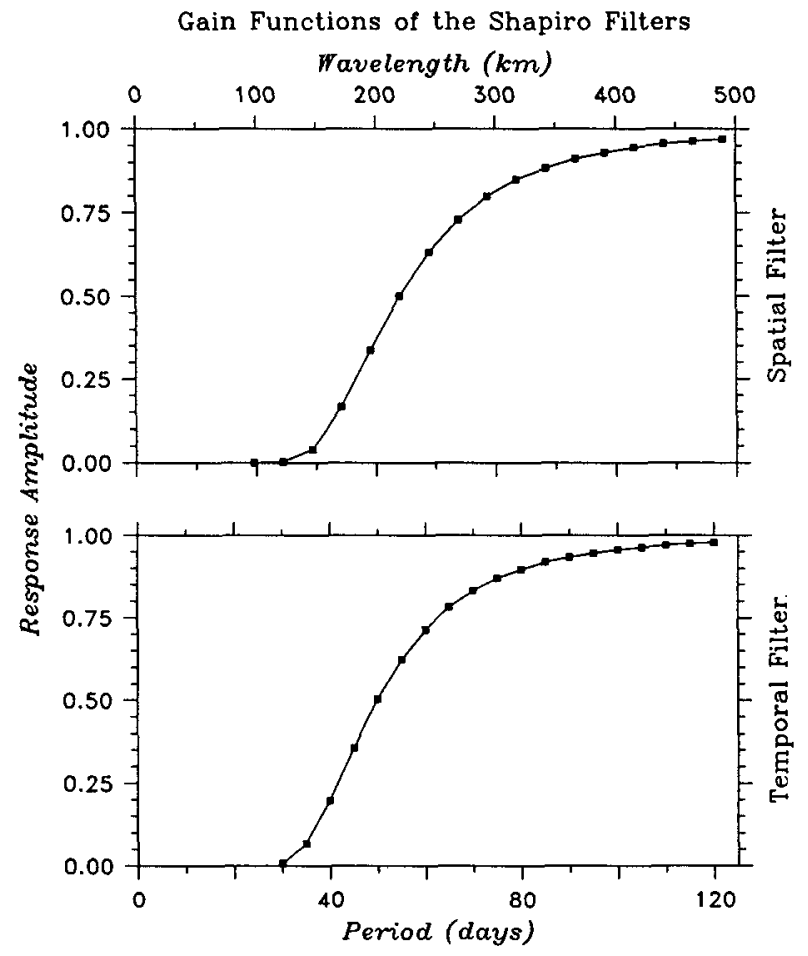

FIG. 3. The gain functions of both the two-dimensional isotropic spatial filter (top) and the one-dimensional temporal filter (bottom) used on the $T_{s}$ maps. The filters were designed using the algorithm developed by Shapiro (1970). 


\section{Anomaly heat balance in a slab mixed layer}

For the purpose of assessing the physical processes responsible for the westward-propagating anomaly features, we consider the anomaly heat balance in a slab mixed layer as described by Frankignoul (1985). By separating variables into seasonal (denoted by an overbar) and anomaly components (denoted by subscript $a$ ), then subtracting the seasonal heat balance, the anomaly heat balance is obtained:

$$
\frac{\partial T_{s a}}{\partial t}=F,
$$

where

$$
\begin{aligned}
& \left(\bar{h}+h_{a}\right) F=-\frac{Q_{a}}{\rho c_{p}}-\left(h \mathbf{v}_{g}\right)_{a} \cdot \nabla\left(\bar{T}_{s}+T_{s a}\right) \\
& \quad-\frac{\left(\vec{\tau}_{a} \times \mathbf{k}\right)}{\rho f} \cdot \nabla\left(\bar{T}_{s}+T_{s a}\right)-h_{a} \frac{\partial \bar{T}_{s}}{\partial t} \\
& \quad-\Lambda\left(\bar{w}_{e}+w_{e a}\right)\left(T_{s a}-T_{+a}\right)-\Lambda w_{e a}\left(\bar{T}_{s}-\bar{T}_{+}\right),
\end{aligned}
$$

and where $h$ represents mixed layer depth, $Q$ net surface heat flux, $\rho$ water density, $c_{p}$ specific heat, $\mathbf{v}_{g}$ horizontal geostrophic current, $\vec{\tau}$ wind stress, $f$ Coriolis parameter, $\mathbf{k}$ vertical normal vector, $w_{e}$ vertical entrainment velocity at the mixed-layer base given by

$$
w_{e}=\frac{\partial h}{\partial t}+\nabla \cdot(h \mathbf{v})
$$

and subscript + a depth just beneath the mixed layer base. The parameter $\Lambda$ in (2) is 0 for $w_{e}<0$ and 1 otherwise because detrainment does not affect $T_{s}$. It has been assumed that $T_{s}$ equals the bulk mixed-layer temperature. Horizontal diffusion has been neglected. We have assumed that horizontal heat advection is dominated by two processes: anomalous geostrophic transport due to the eddy field and wind-driven ageostrophic Ekman transport. Advection by long-term mean geostrophic currents is neglected for reasons discussed in section 7 . Term 1 on the right side of (2) represents the influence of net surface vertical heat flux, term 2 horizontal eddy currents, term 3 Ekman transport, term 4 a modification of $\partial T_{s a} / \partial t$ due to changes of $\bar{T}_{s}$ in the presence of anomalous mixed-layer thickness, and terms 5 and 6 net vertical heat flux at the mixed-layer base. Eddies can force anomalies by producing variability in $h_{a},\left(h v_{g}\right)_{a}, w_{e a}$, and $T_{+a}$, while atmospheric variability can force anomalies by producing variability in $Q_{a}, \vec{\tau}_{a}, h_{a}$, and $w_{e a}$, in (2). Limited available data prevents most of the terms in (1) and (2) from being estimated, but limited progress toward understanding how the observed propagating anomaly features are forced can still be made.

\section{Atmospheric versus eddy forcing}

Models of the low-frequency response of $T_{s a}$ to the atmosphere have assumed that this response consists of two parts: forcing dominated by synoptic-scale ( 2 day to 2 week period) atmospheric variability, and a low-frequency linear feedback mechanism. Atmospheric forcing can thus be considered a stochastic random variable at the low frequencies of $T_{s}$ anomaly variability (e.g., Frankignoul and Hasselmann 1977). Since high-frequency stochastic forcing functions in undamped linear models will produce a low-frequency response that always increases in amplitude with time (Hasselmann 1976), synoptic atmospheric variability is assumed to generate low-frequency $T_{s}$ anomalies by this process. The linear low-frequency feedback mechanism, with the net surface vertical heat flux providing the major contribution (Frankignoul 1985), limits anomaly magnitude. Tests of this two-part model of atmospheric forcing have successfully predicted many properties of low-frequency $T_{s}$ anomalies in openocean regions where the influence of eddies and mean currents on the mixed-layer heat balance are relatively unimportant (e.g., Frankignoul and Hasselmann 1977; Reynolds 1979; Frankignoul 1981; Frankignoul and Reynolds 1983). Decomposing $F$ into stochastic atmospheric forcing $\left(F_{A}\right)$ and linear feedback components, the resulting simplified heat balance model is

$$
\frac{\partial T_{s a}}{\partial t}+\lambda T_{s a}=F_{A},
$$

where $\lambda$ is the feedback coefficient obtained by estimating $\partial F / \partial T_{s a}$.

This model has been tested in the frequency domain in the open ocean by taking the Fourier transform of (4) and deriving the autospectrum of $T_{s a}\left(S_{T T}\right)$ as a function of the autospectrum of $F_{A}\left(S_{F_{A} F_{A}}\right)$ (e.g., Reynolds 1979; Frankignoul and Reynolds 1983; Frankignoul 1985). Since fluctuations of $F$ in (2) are dominated by synoptic-scale atmospheric variability, previous studies have assumed that $F_{A} \approx F$, and thus that $S_{F_{A} F_{A}} \approx S_{F F}$. The Fourier transform of (4) is then given by

$$
S_{T T}=\frac{S_{F F}}{\omega^{2}+\lambda^{2}} .
$$

Since $S_{F F}$ is nearly white at the low frequencies of the anomalies, it is usually considered to be constant.

Frankignoul (1981) has tested this model using the Panulirus hydrographic data taken southeast of Bermuda, a location within the northeastern part of our analysis domain. Using estimates of $S_{F F}$ and $\lambda$ obtained by Reynolds (1979), he found that $S_{T T}$ estimated from data was significantly more energetic than $S_{T T}$ predicted by (5) at periods of $O(100)$ days. He attributed this additional variance to the influence of the baroclinic 
eddy field on $T_{s a}$, which is not represented in the model (4). He also noted that when $T_{s a}$ is smoothed over regions of $\mathrm{O}(1000) \mathrm{km}$ in size, thus averaging out eddyscale variability, the estimated autospectrum closely resembles the predicted one. We will essentially repeat this test here to verify that the propagating anomaly features cannot be driven solely by local stochastic atmospheric forcing.

The autospectrum of $T_{s a}$ predicted from (5) using estimates of $S_{F F}$ and $\lambda$ representative of the Sargasso Sea obtained from Reynolds (1979) is white at frequencies less than 0.5 cycles per year (cpy) (Fig. 4) and becomes red at higher frequencies. An autospectrum of the time series of $T_{s}$ averaged over nearly the entire analysis domain to suppress eddy-scale variability follows the predicted one reasonably well at all frequencies between 0.6 and 6 cpy (Fig. 4). In contrast, local autospectra representative of the northern, central, and southern parts of the analysis domain were all more energetic than the predicted autospectrum between frequencies of 1.5 and $6 \mathrm{cpy}$, with the difference approximately equalling the width of the $95 \%$ error bar (Fig. 4). These results confirm the conclusions reached by Frankignoul (1981). The autospectra for the north-

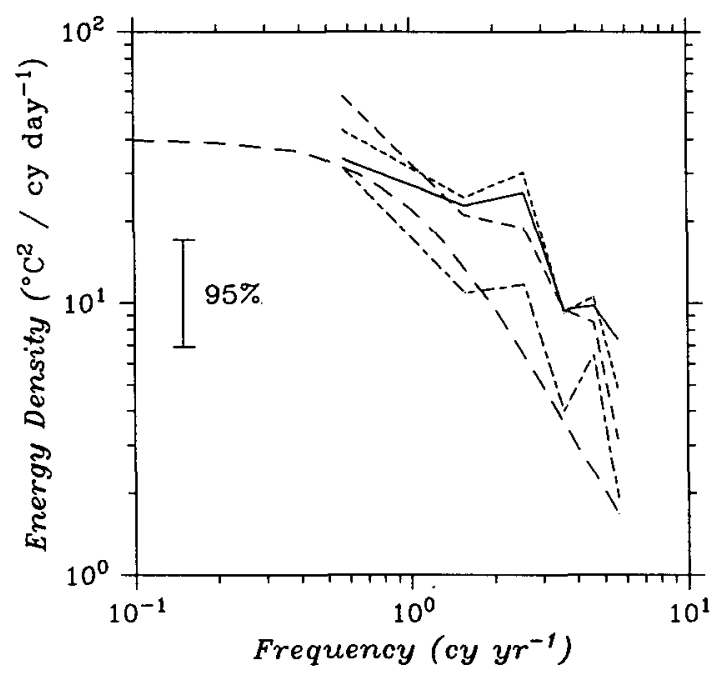

Fig. 4. Temporal autospectra of $T_{s a}$. The long dashed line is the autospectrum predicted using (5). The short/medium-dashed line is the autospectrum of the time series of $T_{s a}$ averaged over the entire domain, excluding the points in the northwest corner influenced by the Gulf Stream (Fig. 6), which represents the autospectrum of verylarge-scale $T_{s a}$ fluctuations. The other three functions represent the local autospectrum in the northern, central, and southern parts of the domain. The solid line is the ensemble average of autospectra calculated at all grid points between $30.5^{\circ}$ and $32.5^{\circ} \mathrm{N}$. The shortdashed line is the ensemble average of autospectra calculated at all grid points at $28^{\circ} \mathrm{N}$. The medium-dashed line is the ensemble average of autospectra calculated at all grid points between $22.5^{\circ}$ and $24.5^{\circ} \mathrm{N}$. The width of the $95 \%$ confidence limits based on 42 degrees of freedom is shown. Spectral estimates were averaged over seven frequency bands and the ensemble averaging was assumed to span three zonal correlation scales.

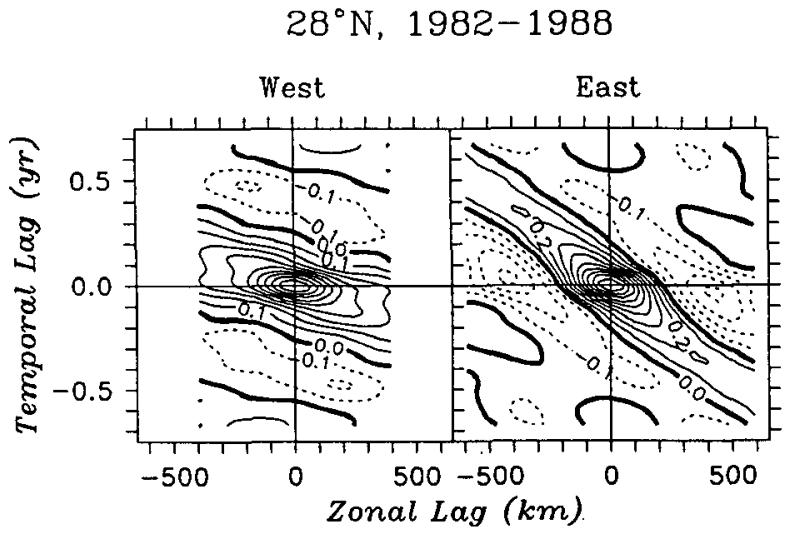

FIG. 5. Zonal-time autocorrelation functions of $T_{s a}^{\prime}$ at $28^{\circ} \mathrm{N}$, calculated using the entire 7-year set of maps, for the western and eastern subdomains separated by the $71^{\circ} \mathrm{W}$ meridian. Dashed contours in this and all subsequent contour plots indicate negative values.

ern and central parts of the domain have a peak confined between about 1.5 and 3 cpy, a band containing the dominant frequency of the large-scale anomaly features. This peak is barely evident in the southern part.

\section{Properties of the propagating anomaly features \\ a. Basic properties}

We first demonstrate that the westward-propagating anomaly features are only found between $26^{\circ}$ and $32^{\circ} \mathrm{N}$ east of $71^{\circ} \mathrm{W}$. Two-dimensional zonal-time autocorrelation functions (Fig. 5), calculated using zonaltime matrices of $T_{s a}^{\prime}$, are used to illustrate this confinement. If a propagating signal dominates the data, then the central correlation peak will assume an elongated shape with the major axis orientation providing a rough estimate of the zonal phase propagation velocity. Since correlation functions are integral functions of the data, they tend to emphasize the larger-scale, lower frequency variability contained in the data. Thus, the autocorrelation functions presented in the present study are very effective at revealing properties of the observed large-scale, low-frequency propagating anomaly features. At $28^{\circ} \mathrm{N}$, the westward propagation speed of the propagating anomaly features is $\sim 3-4 \mathrm{~km}$ $\mathrm{day}^{-1}$ to the east of $71^{\circ} \mathrm{W}$ (Fig. 5). However, the central correlation ridge for the $T_{s a}^{\prime}$ fluctuations west of $71^{\circ} \mathrm{W}$ is much more closely aligned with the zonal lag distance axis, making a propagation speed difficult to determine.

A change in anomaly properties at $71^{\circ} \mathrm{W}$ is also revealed in the rms amplitude map of $T_{s a}^{\prime}$ (Fig. 6). A relative maximum in the rms amplitude of $T_{s a}^{\prime}$ is evident in a zonal band centered between about $27^{\circ}$ and $29^{\circ} \mathrm{N}$ to the east of $71^{\circ} \mathrm{W}$ (Fig. 6), with zonal bands of minimum amplitude evident to the south between $23^{\circ}$ and $26^{\circ} \mathrm{N}$ and to the north between $31^{\circ}$ and $33^{\circ} \mathrm{N}$. 


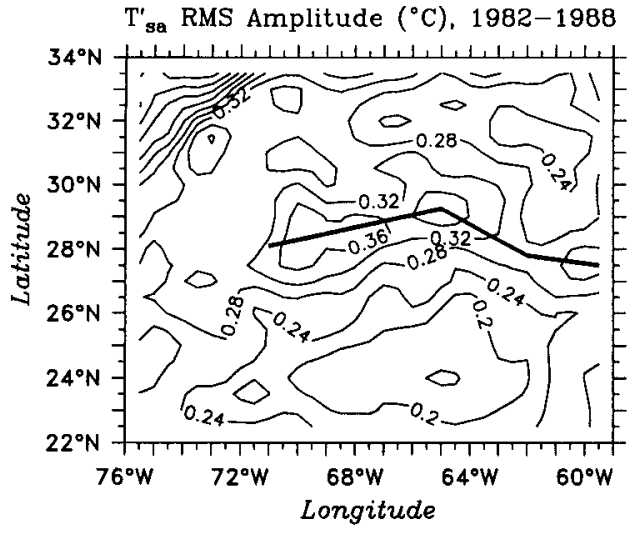

FIG. 6. The rms amplitude of $T_{s a}^{\prime}$ fluctuations for the entire 7year period. The dark line traces the zonal band of maximum amplitude within the STCZ east of $71^{\circ} \mathrm{W}$.

It is unclear why abrupt changes occur near $71^{\circ} \mathrm{W}$, but we suspect that the influence of the western boundary region begins to be felt there. Olson, et al. (1984) noted that the influence of the Gulf Stream recirculation apparently extends to the south of $28^{\circ} \mathrm{N}$ near the western end of our analysis domain, so this could be a factor. The increasing amplitudes of $T_{s a}^{\prime}$ north of $33^{\circ} \mathrm{N}$ in Fig. 6 may be caused by Gulf Stream cold-core rings, which are encountered with rapidly increasing frequency to the north of that latitude (Ebbesmeyer and Taft 1979). The relatively large amplitudes in the northwest corner of the domain are caused by the occasional offshore migration of Gulf Stream water.

Two-dimensional zonal-time autocorrelation functions (Fig. 7), calculated using $T_{s a}^{\prime}$ maps at several latitudes between $23^{\circ}$ and $33^{\circ} \mathrm{N}$, reveal the meridional confinement of the anomaly features east of $71^{\circ} \mathrm{W}$. Westward phase propagation at $3-4 \mathrm{~km} \mathrm{day}^{-1}$ is clearly evident between about $26^{\circ}$ and $32^{\circ} \mathrm{N}$, with the strongest evidence (the most-elongated central correlation peak) observed at $28^{\circ} \mathrm{N}$ (Fig. 7). Relatively weak evidence of westward propagation (less-elongated central correlation peaks in Fig. 7) exists north of $32^{\circ} \mathrm{N}$. Phase propagation is not evident south of about $25^{\circ} \mathrm{N}$. A meridional asymmetry thus exists, with the propagating signal decaying more sharply toward the south than toward the north. Characteristic periods and zonal wavelengths can be roughly estimated from the correlation function at $28^{\circ} \mathrm{N}$ as the distances along the lag axes to the first correlation minimum, and are $\sim 800 \mathrm{~km}$ and $\sim 200$ days.

The two-dimensional horizontal structure and propagation velocity of the features were determined by calculating a three-dimensional autocorrelation function of the $T_{s a}^{\prime}$ field over the entire seven-year interval within the subdomain between $26^{\circ}$ and $32^{\circ} \mathrm{N}$ east of $71^{\circ} \mathrm{W}$ (Fig. 8). The shift of the central correlation peak in zonal-meridional lag distance space as a function of increasing lag time provides an estimate

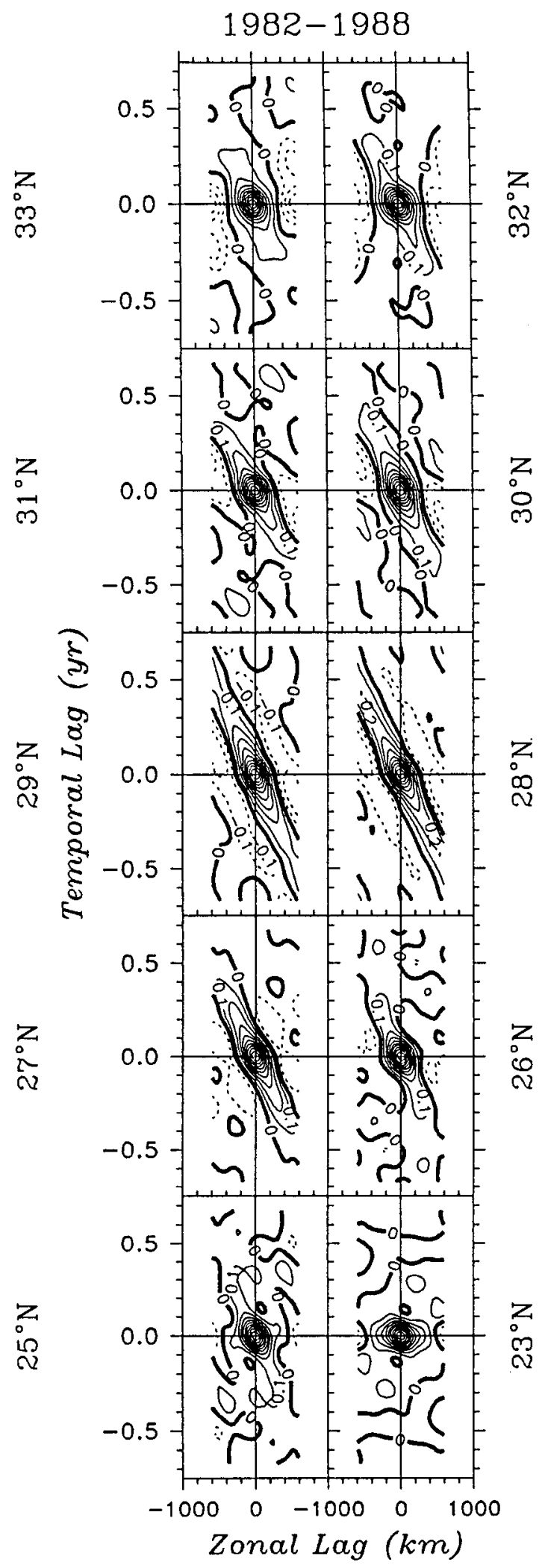

FIG. 7. Zonal-time autocorrelation functions of $T_{s}$ at all integer latitudes except $24^{\circ} \mathrm{N}$ (which was similar to the function at $23^{\circ} \mathrm{N}$ ), calculated using the entire 7-year set of $T_{s}$ maps. 


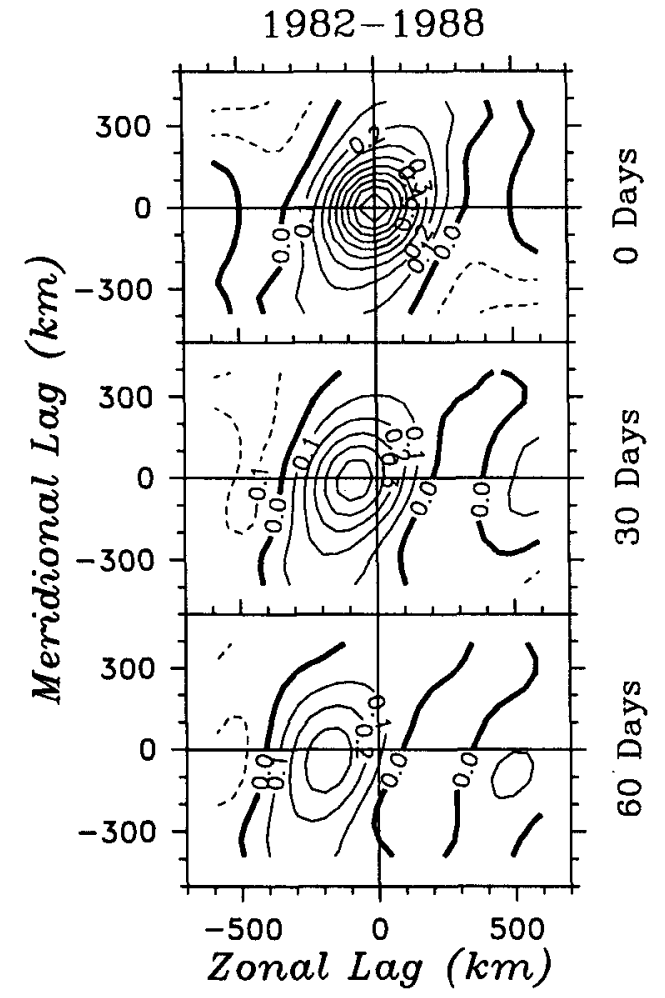

FIG. 8. Three-dimensional autocorrelation function of $T_{s a}^{\prime}$ over the entire 7-year period, calculated for the subdomain between $26^{\circ}$ and $32^{\circ} \mathrm{N}$ east of $71^{\circ} \mathrm{W}$.

of the phase propagation velocity of the anomaly features, which was almost due west at $3-4 \mathrm{~km}$ day $^{-1}$. The shape of the central correlation peak at zero lag time reveals the average characteristic structure of the propagating anomaly features, which were anisotropic with the major axis oriented SSW-NNE. The central correlation peak is still evident after 75 days lag time (not shown), although the maximum positive correlation has decreased to about 0.3 .

\section{b. Seasonal and interannual variability}

Three-dimensional autocorrelation functions of $T_{s a}^{\prime}$ calculated in the same subdomain for individual seasons reveal seasonal (winter vs summer) and interannual variability of anomaly properties, with "summer" defined as June-September and "winter" defined as mid-November through mid-May (except for 1982, when it is defined as January through early June). Although the statistical significance of properties estimated from autocorrelation functions calculated with only a few degrees of freedom is limited, large and potentially important interannual and seasonal differences are suggested by comparing these functions. For the seven winter seasons, the structure of the central correlation peaks at zero lag time differs from year to year (Fig. 9), suggesting that interannual variability exists in the characteristic spatial structure of the anomaly features. The features were spatially isotropic during 1986-87, and spatially anisotropic during the other winters with variable major axis orientation. If eddies force the anomalies, then these differences in anomaly structure could reflect differences in eddy structure. The features propagated almost due west at either 3.3 or $3.9 \mathrm{~km} \mathrm{day}^{-1}$ during all years as revealed by the shift of the central correlation ridge after a time lag of 30 days (Fig. 9). Propagation speed estimates were made using the function at a lag time of 75 days (not shown), and the two discrete values resulted from the minimum lag space resolution of the correlation function. The factors governing propagation speed thus remains remarkably constant from year to year. Temporal persistence of the anomaly features was very short during 1984-85, with the central correlation peak nearly disappearing after 30 days lag time (Fig. 9). Much longer persistence occurred during the other years, especially during $1982,1982-83$, and 1985-86 (FASINEX). Consequently, the effectiveness of the forcing mechanisms responsible for the generation and maintenance of the propagating anomaly features may vary substantially from year to year.

Summer three-dimensional autocorrelation functions of $T_{s a}^{\prime}$ (Fig. 10) reveal major seasonal differences. Summer features generally have larger space scales and larger interannual variability in spatial structure than winter features. In contrast to winter, clear evidence of westward propagation is not evident after 30 day lag times because the central correlation peaks have essentially disappeared. However, evidence of westward propagation at a speed similar to winter is still evident after 15 days lag time (Fig. 10). Although propagation is evident, propagating features are much weaker and much less persistent during summer. It may be that at least some of the forcing mechanisms responsible for the westward-propagating anomaly features still operate during summer, but other processes operating during summer prevent strong, persistent anomaly features from being generated. For example, the contribution of horizontal eddy currents to anomaly forcing in (2) will be weaker during summer because the seasonal mean meridional $T_{s}$ gradient in the STCZ is weaker then. Also, the vertical temperature gradient just beneath the mixed layer is much stronger during summer, tending to suppress mixed-layer entrainment.

\section{Eddy forcing \\ a. Statistical clues}

Since we do not have the data to directly calculate the influence of eddies on $T_{s a}$ in (1) and (2), we employ indirect statistical analyses to show that eddies are probably responsible for forcing the anomalies and to characterize the nature of this forcing. We first determine if the zonal dispersion of surface anomaly features 


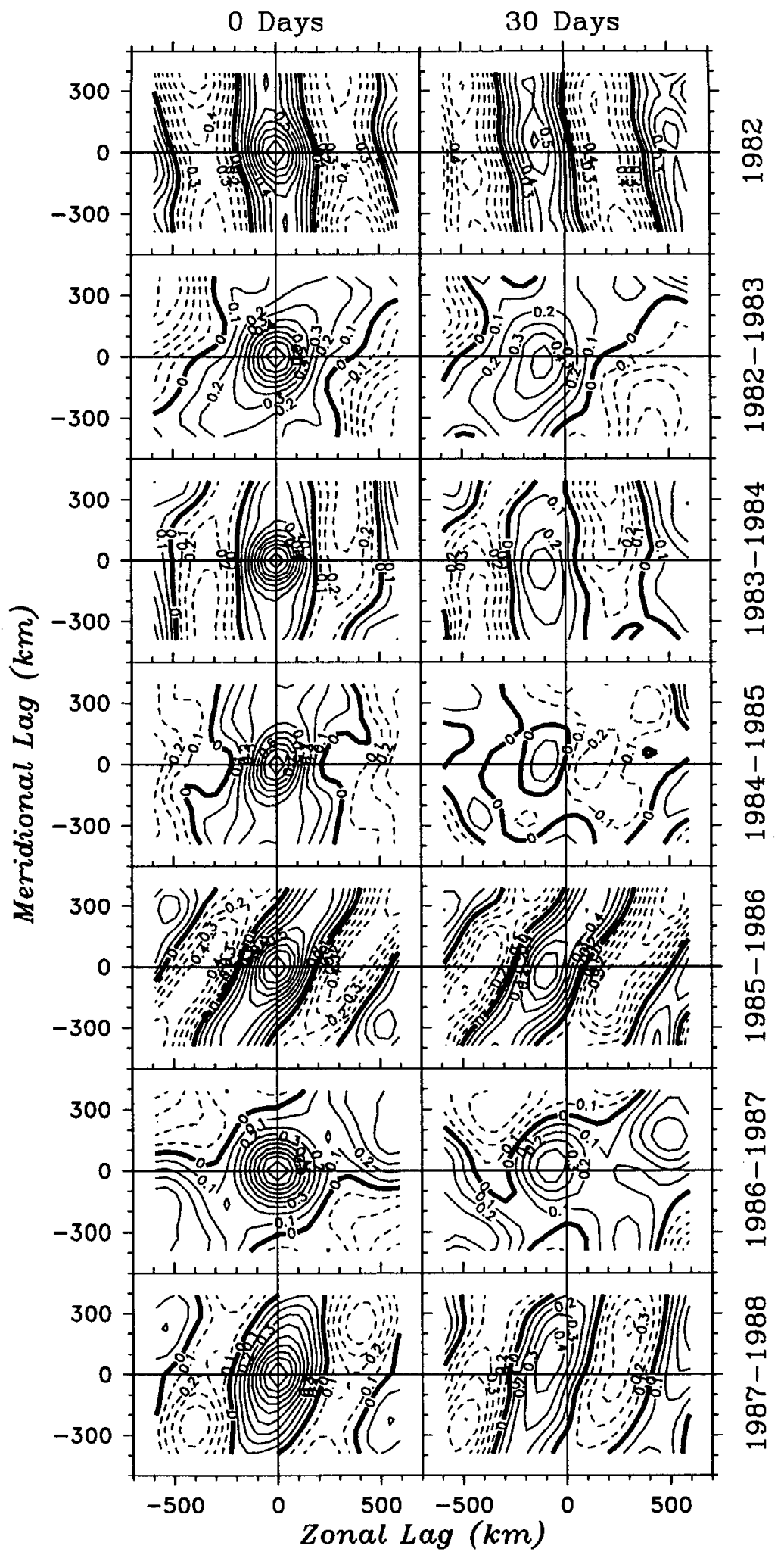

FIG. 9. Three-dimensional autocorrelation functions of $T_{s a}^{\prime}$ for 7 "winter" seasons (mid-November through mid-May, except for January through early June in 1982) at lag times of 0 and 30 days calculated for the subdomain between $26^{\circ}$ and $32^{\circ} \mathrm{N}$ east of $71^{\circ} \mathrm{W}$. 


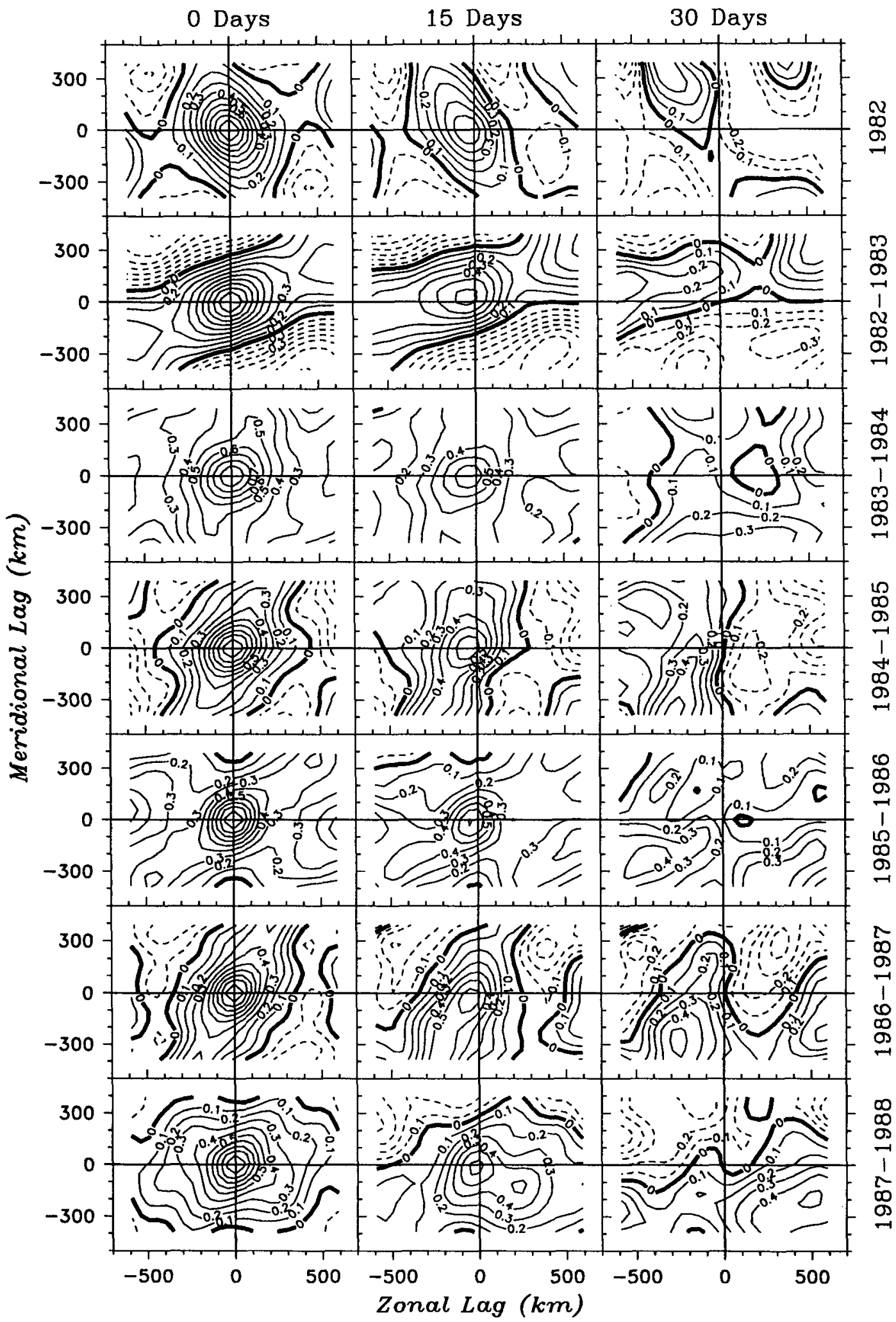

FIG. 10. As in Fig. 9 except for 7 "summer" (June through September) seasons and also including the functions at 15 day lag times. 
is consistent with the expected properties of baroclinic eddies. We calculated zonal-time autospectra (e.g., Pratt 1976) at each latitude from the $T_{s a}^{\prime}$ field using two-dimensional Fourier transforms. They were calculated for positive frequency only, so the estimates for negative (positive) wavenumbers represent westward (eastward) propagating variance. Because of the large space and time scales of the anomaly features, the basic properties of baroclinic eddies with these same scales can be accounted for reasonably well using linear Rossby wave dynamics. To test if the anomalies may be coupled to such eddies, we determine if $T_{s a}^{\prime}$ variance density in the autospectra tends to be concentrated near a Rossby wave zonal dispersion curve, which is given by

$$
\omega=\frac{-\beta k}{k^{2}+l^{2}+a^{-2}},
$$

where $a$ is the internal radius of deformation of the mode. Since the surface anomaly features propagate almost due west, and since the features are usually more elongated meridionally than zonally, we assume that $l$ $\ll k$.

We present representative zonal-time autospectra north, within, and south of the latitude band strongly influenced by propagating anomaly features (Fig. 11). Dispersion curves for a single Rossby wave mode (Fig. 11) were calculated from (6) using $a=45 \mathrm{~km}$, which was estimated for the first Rossby wave mode in the FASINEX region (Brink, personal communication). The dominance of westward-propagating $T_{s a}^{\prime}$ variance at $28^{\circ} \mathrm{N}$ is clearly evident in Fig. 11. The dispersion curve tends to follow the ridge of large energy density for negative wavenumbers $<2.2 / 1000 \mathrm{~km}$ in magnitude (wavelengths $>450 \mathrm{~km}$ ). At larger negative wavenumbers, the maximum energy density exists at somewhat higher frequency than predicted by the dispersion curve. A peak in the energy density that exceeds $10^{5.2}$ in magnitude exists in the negative wavenumber side of the spectrum in the $(-k, \omega)$ band containing the characteristic wavelength and period $(800 \mathrm{~km}$ and 200 days) of the propagating anomalies estimated from correlation functions (Fig. 11). Westward-propagating variance at this wavelength and period exceeds eastward-propagating variance by an order of magnitude. The long-wave zonal phase velocity estimated from this spectrum is almost identical to the propagation velocity estimated previously using correlation functions.

A detailed intercomparison between the two-dimensional autospectra and the dispersion curves is not warranted. Besides the fact that the surface anomalies are not a perfect tracer of the underlying eddy field, more than one mode may make a significant contribution to the wave field, the presence of mean current and current shear will modify the dispersion properties of the eddy field (e.g., Kang and Magaard 1982), and nonlinear effects should become more important with increasing $|k|$. Still, this dominance of westward-
$\mathrm{T}_{\text {sa }}$ Zonal-Time Autospectrum

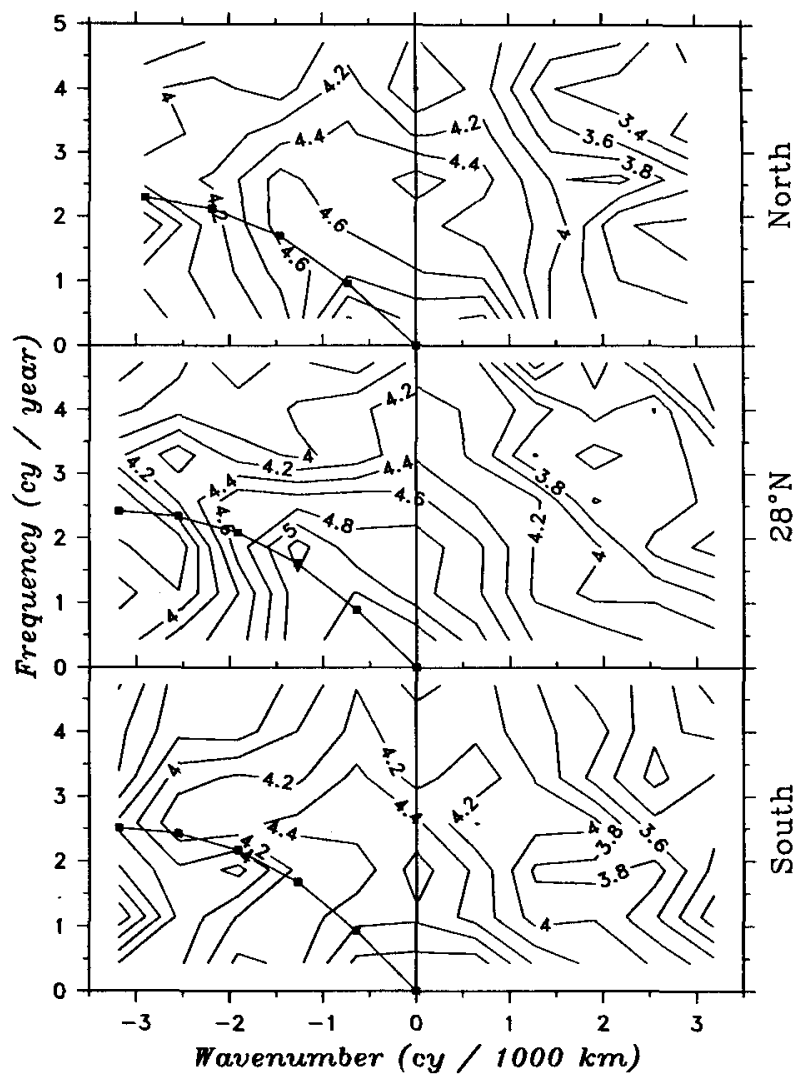

FIG. 11. Zonal-time autospectra of $T_{s a}^{\prime}$ north (top), within (center), and south (bottom) of the latitude band strongly influenced by westward-propagating anomalies. The five autospectra between $30.5^{\circ}$ and $32.5^{\circ} \mathrm{N}\left(22.5^{\circ}\right.$ and $\left.24.5^{\circ} \mathrm{N}\right)$ were averaged together to calculate single autospectra representative of the region north (south) of the latitude band. The autospectrum at $28^{\circ} \mathrm{N}$ was used to represent the variability within the band. These are the same latitude bands used for estimating the local frequency autospectra in Fig. 4 . The base 10 logarithm of the energy density is contoured. The autospectrum north of the band was calculated over all longitudes. east of $73^{\circ} \mathrm{W}$ to eliminate the influence of the Gulf Stream in the northwest corner (Fig. 6). The other two autospectra were calculated over all longitudes to maximize the wavenumber resolution. Autospectra calculated only over longitudes east of $71^{\circ} \mathrm{W}$ closely resembled these autospectra. Spectrum estimates at each wavenumber were averaged over 5 frequency bands to yield 10 degrees of freedom. At each $(k, \omega)$, the $95 \%$ confidence limits range from the estimate minus 0.31 to the estimate plus 0.49 . Dispersion curves calculated from (6) assuming that $l=0$ are graphed for each autospectrum for a $50 \mathrm{~km}$ radius of deformation.

propagating variance is suggestive of eddy forcing and it cannot be accounted for by the stochastic forcing model (4). The zonal-time autospectrum predicted by this model is also given by (5), so westward-propagating variance can dominate the response only in those $(k, \omega)$ bands where westward-propagating variance dominates the atmospheric forcing. Atmospheric variability does not have a preferred zonal propagation direction at the low frequencies of the anomalies (e.g., Willebrand 1978). 
South of the frontal zone, a ridge of large energy density following the Rossby wave dispersion curve is not evident (Fig. 11). Instead, an excess of westwardpropagating variance exists near 3 cpy over all wavenumbers. To the north of the frontal zone, a ridge of large energy density does roughly follow the dispersion curve, although the statistical significance of this ridge is marginal (Fig. 11).

\section{b. Forcing mechanisms}

The influence of horizontal eddy currents on $T_{s a}$, represented by term 2 on the right side of (2), is known to be important in the Sargasso Sea. For example, closed eddies in the MODE region advected cold (warm) mixed-layer water southward (northward) around their peripheries (Voorhis et al., 1976). This characteristic signature of the influence of horizontal heat advection by eddy currents has been modeled by Nelepo et al. (1978). Frankignoul (1981) used Panulirus hydrographic data to calculate the cross-correlation function between surface and deeper temperature, detecting a significant correlation at a temporal phase lag indicative of surface anomalies existing at the peripheries of the underlying eddies. He therefore concluded that horizontal heat advection probably had a significant influence on $T_{s}$. In contrast, some evidence exists that surface anomalies may not always appear on the periphery of eddies. Analyses described in Halliwell and Cornillon (1989) and Halliwell (1990) suggested that large-scale $T_{s}$ anomaly features were roughly in-phase with deeper temperature fluctuations within the Sargasso Sea STCZ, at least at times. Nearly in-phase relationships between surface and deeper temperature perturbations have been detected in the Sargasso Sea by Shen et al. (1986), and also in the North Pacific STCZ by Camp and Elsberry (1978) and Van Woert (1982). Thus, processes other than horizontal eddy currents may also be important. For example, the eddy field can modify the vertical entrainment velocity and the temperature jump at the mixedlayer base, thus influencing $T_{s}$ through the rightmost two terms of (2). Aspects of this influence have been modelled by Stevenson (1983) and Klein and Hua (1988).

The meridional confinement of the anomalies may yield clues to the nature of the eddy forcing mechanisms. One possibility is that properties of the eddy field vary meridionally in such a manner that they more effectively force anomalies near $28^{\circ} \mathrm{N}$. Previous studies of eddy potential and kinetic energy distribution in the Atlantic Ocean (e.g., Dantzler 1977; Emery 1983; Ebbesmeyer and Taft 1979; Robinson et al., 1983) indicate that the anomaly band does not coincide with a band of relatively large eddy energy. Also, Sturges and Summy (1982) demonstrated that eddies with the wavelengths, frequencies, and westward propagation speed of the anomaly features observed here were pres- ent between Bermuda and a weather station to the east. Since both of these stations were located north of the anomaly band, the eddies cannot be as sharply confined to a zonal band as the anomalies.

Another possibility is that the large mean meridional $T_{s}$ gradients in the STCZ enhance the influence of horizontal eddy currents on $T_{s a}$ through the second term on the right side of (2). We compare the meridional variability of several parameters to partly answer this question. To represent the mean meridional surface temperature structure of the subtropical frontal zone during winter, we averaged $T_{s}$ zonally between $71^{\circ}$ and $59.5^{\circ} \mathrm{W}$ at each latitude and temporally over the first four months of all seven years (a total of 28 months). We used the January through April period to represent the mean winter front here because temperature gradients are most strongly developed then. The meridional gradient of this meridional $T_{s}$ profile $\left(\bar{T}_{s y}\right)$ is graphed as a function of latitude in Fig. 12. The mean zonally averaged temperature frontal zone at the surface is several degrees of latitude wide. The maximum magnitude of $\left(\bar{T}_{s y}\right)$ is about $6^{\circ} \mathrm{C}$ per 1000 $\mathrm{km}$, and it is nearly constant at this value between $26.5^{\circ}$ and $30^{\circ} \mathrm{N}$. The filtering performed only allows variability with meridional wavelengths $>1-2^{\circ}$ latitude to be resolved.

A band of relatively large zonally-averaged (east of $\left.71^{\circ} \mathrm{W}\right) T_{s a}^{\prime}$ variance is confined between about $26.5^{\circ}$ and $31.5^{\circ} \mathrm{N}$ (Fig. 12). In contrast to the flat $\bar{T}_{s y} \max -$ imum, a peak exists at $29^{\circ} \mathrm{N}$. The rms amplitude at $29^{\circ} \mathrm{N}$ is about $40 \%$ larger than at $24^{\circ} \mathrm{N}$ and about $25 \%$ larger than at $32^{\circ} \mathrm{N}$. By integrating zonal-time autospectra over wavenumber and frequency separately for the $+k$ and $-k$ sides, eastward and westward-propagating variance can be estimated separately. The largest

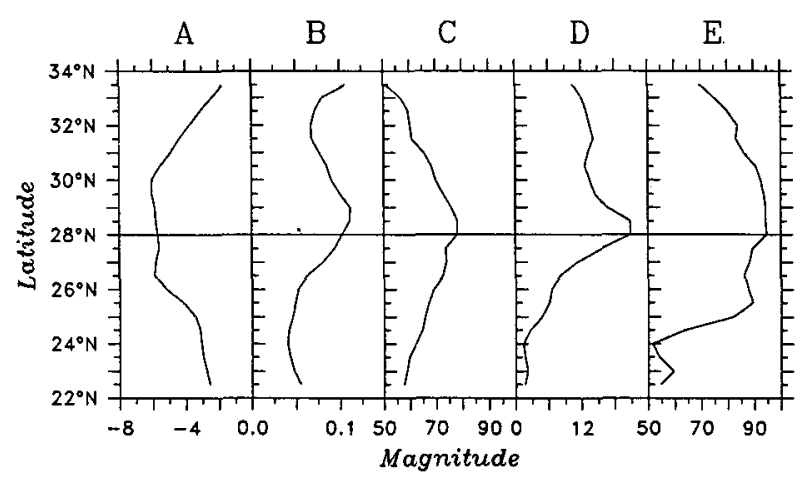

FIG. 12. Meridional dependence of several parameters over longitudes east of $71^{\circ} \mathrm{W}$ : the meridional gradient of zonally averaged temperature $\bar{T}_{s y}$ in ${ }^{\circ} \mathrm{C} \mathrm{m}^{-1}$ multiplied by $10^{6}(\mathrm{~A})$, the variance of $T_{s a}^{\prime}$ in ${ }^{\circ} \mathrm{C}^{2}$ determined by integrating zonal-time autospectra over both $k$ and $\omega$ (B), the percentage of this variance that propagates westward $(\mathrm{C})$, the variance density of $T_{s a}^{\prime}$ at the relative maximum of energy density in the zonal-time autospectra contained in the $(k$, $\omega)$ band centered near a wavelength of $800 \mathrm{~km}$ and a period of 200 days and multiplied by $10^{3}(\mathrm{D})$, and the percentage of this variance density that propagates westward (E). 
percentage of westward-propagating variance $(\sim 80 \%)$ exists at $28^{\circ} \mathrm{N}$, with a nearly equal percentage existing at $28.5^{\circ} \mathrm{N}$. This percentage decreases approximately linearly both to the north and south of this maximum. We repeat this analysis for the single $(k, \omega)$ band corresponding to a wavelength of $\sim 800 \mathrm{~km}$ and period of $\sim 200$ days. The meridional maximum in the variance density within this $(k, \omega)$ band is more sharply trapped near $28^{\circ} \mathrm{N}$ than the total variance, with a largeamplitude peak confined between about $27^{\circ}$ and $29.5^{\circ} \mathrm{N}$ (Fig. 12). This variance remains nearly constant to the north of $29.5^{\circ} \mathrm{N}$, but falls off rapidly to the south of $27^{\circ} \mathrm{N}$. The percentage of westward-propagating variance density in this $(k, \omega)$ band is largest $(94 \%)$ at $28^{\circ} \mathrm{N}$. This percentage falls off slowly both to the north and south, with the exception of south of $25^{\circ} \mathrm{N}$ where it decreases sharply to just over $50 \%$ by $24^{\circ} \mathrm{N}$.

The meridional distribution of westward-propagating $T_{s}$ variance could well be related to the existence of the enhanced meridional gradients of the STCZ, but a clear relationship cannot be proven from these analyses. The zonally averaged surface front appears as a broad band of uniformly large meridional temperature gradient nearly 4 degrees of latitude wide while meridional distributions of zonally averaged temperature anomaly variance peak sharply within this frontal band.
We also investigated whether the influence of eddies on entrainment at the mixed-layer base may be affecting $T_{s a}$ through the rightmost two terms of (2). The models of Stevenson (1983) and Klein and Hua (1988) predict that relatively strong $T_{s}$ anomalies should appear during periods of mixed-layer deepening, which motivated us to look at how the persistent features appeared during fall. The formation of the very persistent anomalies present during 1985/86 (FASINEX) was particularly interesting. These features are evident between November 1985 and April 1986 in monthly-averaged maps of $T_{s a}^{\prime}$ (Fig. 13). Perhaps most clearly evident is the warm feature located between about $26^{\circ}$ and $32^{\circ} \mathrm{N}$ in all six months. It is located between $68^{\circ}$ and $63^{\circ} \mathrm{W}$ in November 1985 and between $72^{\circ}$ and $66^{\circ} \mathrm{W}$ in April 1986. A persistent cold feature is present to the west of this warm feature. To look more closely at the appearance of these features during fall, five-day maps of $T_{s a}^{\prime}$ that were not subjected to the temporal Shapiro filter (Fig. 3) were contoured between 15 October and 9 November 1985 (Fig. 14). The persistent features evident in Fig. 13 do not appear in the four 5-day maps between 15 October and 30 October. They are, however, clearly evident in the final two maps ( 4 and 9 November) with a hint of their initial formation evident in the 30 October map. Al-

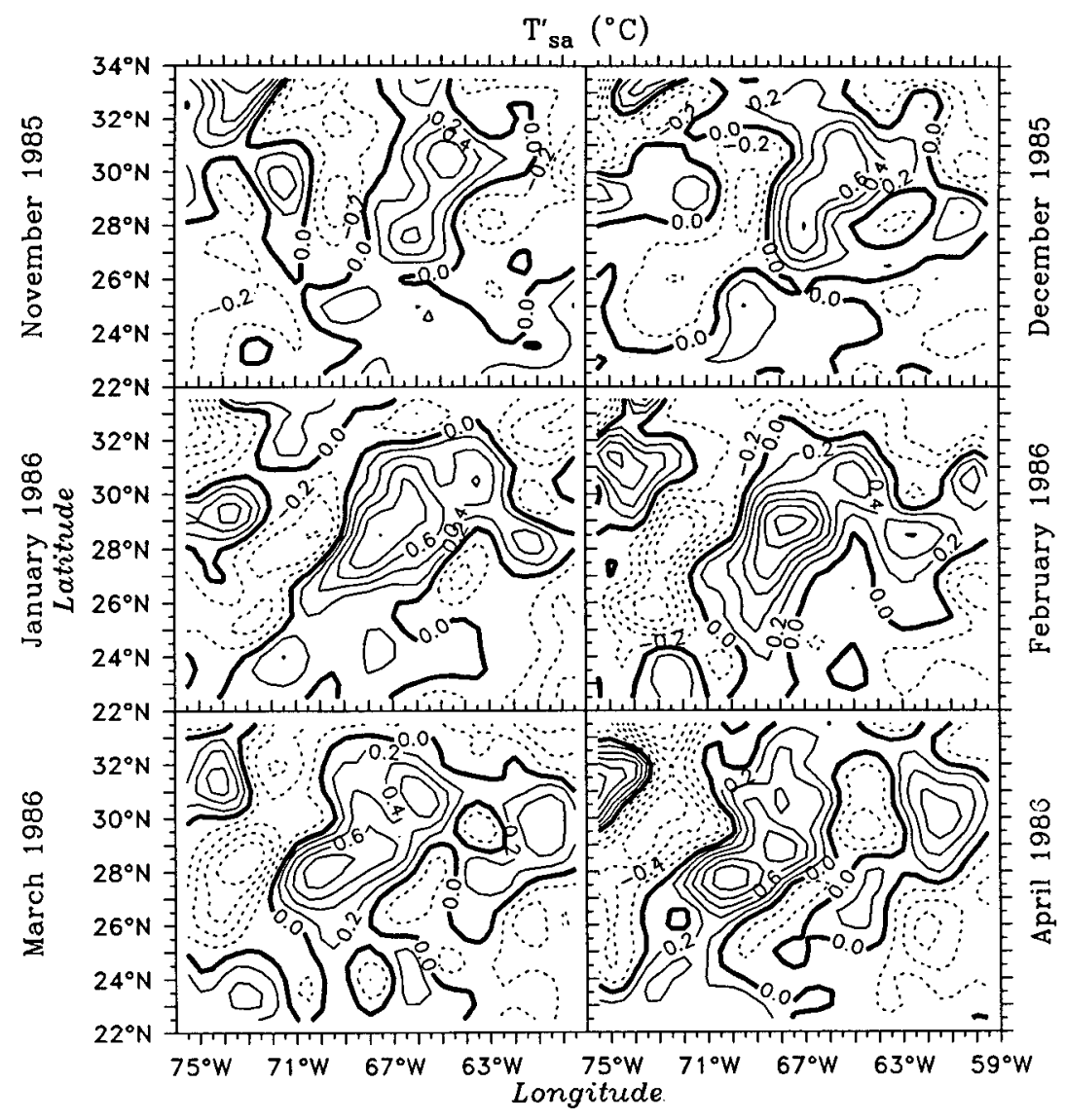

FIG. 13. Monthly-averaged maps of $T_{s a}^{\prime}$ for November 1985 through April 1986. 


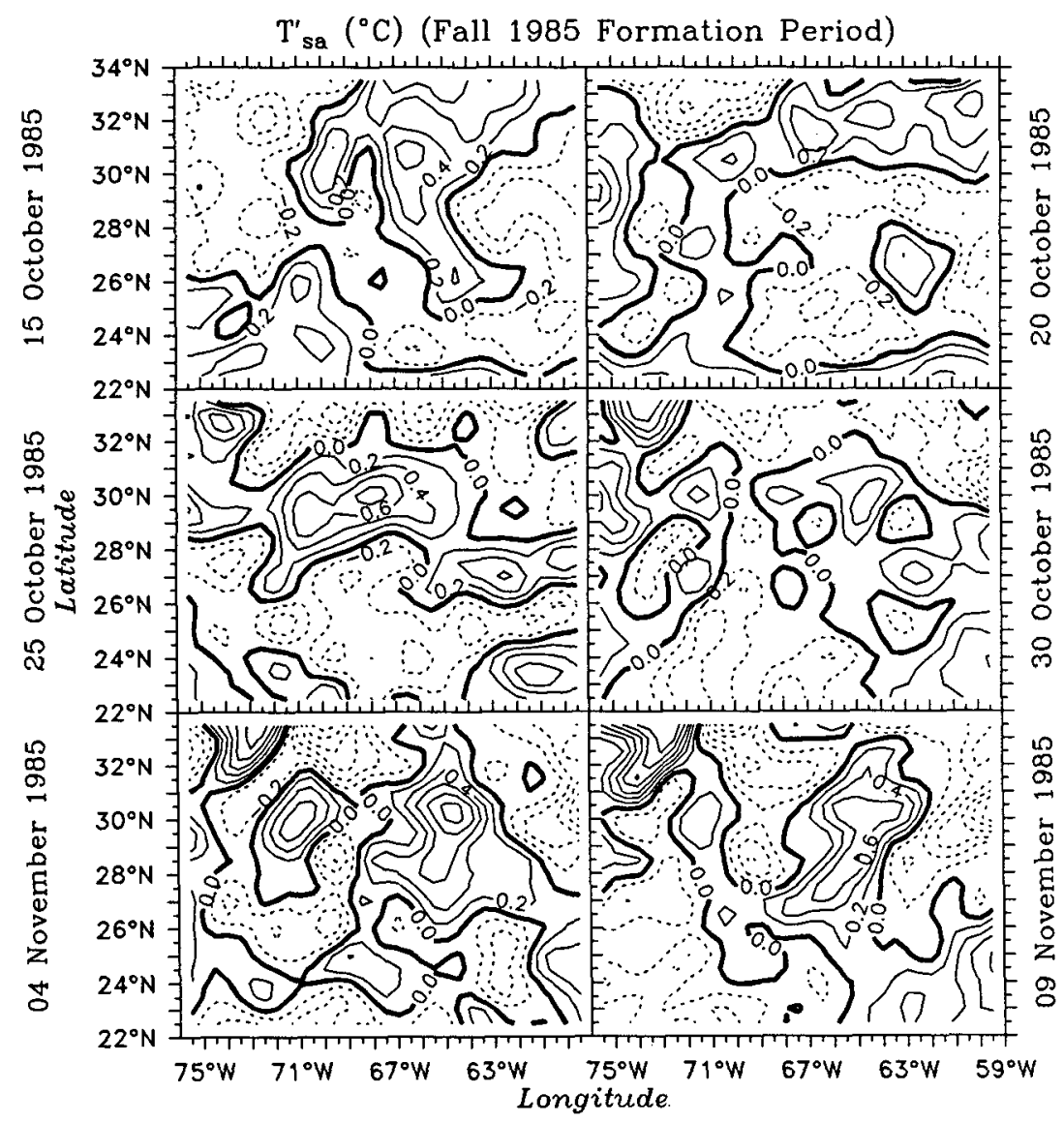

FIG. 14. Five-day maps of $T_{s a}^{\prime}$ for 15 October 1985 through 9 November 1986. These maps are from the $T_{s a}^{\prime}$ data set that has not been temporally filtered using the Shapiro filter (Fig. 3).

though the features persisted for months, their formation was eventlike in that it took only a few days.

Several days is far too short for strong baroclinic eddy features to spin up. It is unlikely that horizontal heat advection due to eddy currents causes the sudden formation. From the second term on the right side of (2), if little change in $\mathbf{v}_{g}$ is assumed to occur over the several-day formation period, then a sudden large increase in $\left|\nabla T_{s}\right|$ would be necessary for rapid formation. Inspection of $T_{s}$ maps showed that this did not occur. Horizontal eddy currents could not have been the dominant process responsible for this rapid formation.

In mixed-layer models were entrainment due to wind-driven turbulence deepens the mixed layer (e.g., Turner and Kraus 1967), the rate of deepening, neglecting the contribution of $h$ and $\left(T_{s}-T_{+}\right)$, is proportional to $u_{*}^{3}=(|\vec{\tau}| / \rho)^{3 / 2}$, the cube of the friction velocity. We calculated $u_{*}^{3}$ using wind fields obtained from the Fleet Numerical Oceanography Center (FNOC) and averaged it over the subdomain between $26^{\circ}$ and $32^{\circ} \mathrm{N}$ east of $71^{\circ} \mathrm{W}$. The time series of spatially averaged $u_{*}^{3}$ for October and November 1985 (Fig. 15) show that with the exception of one short event in early October due to Hurricane Gloria brushing by the sub- domain, $u_{*}^{3}$ was generally smaller prior to the anomaly formation period than either during or after it. The surface anomaly features thus appeared at the onset of relatively stormy fall weather. The increased storminess during fall is occasionally accompanied by cold air outbreaks which stimulate convection, greatly increasing the rate of mixed-layer deepening over that driven by wind-driven turbulence alone. Without surface heat flux estimates, we cannot estimate the total mixed-layer deepening that probably occured during the formation period. The apparent relationship between the appearance of the 1985/86 surface features and the onset of stormy weather is encouraging, but it must remain conjectural until more thorough studies are performed.

The depth of the mixed layer base is also influenced by the Ekman pumping velocity. Positive wind stress curl produces upward vertical velocity which tends to raise the base and thus increase $w_{e}$ in (2). Wind stress curl is normally negative on average in the STCZ, but a plot of wind stress curl averaged over the same subdomain as $u_{*}^{3}$ indicates that the curl was positive on average from about one week prior to the formation period through the end of that period. The average vertical velocity between 20 October and 9 November was $+0.03 \mathrm{~m} \mathrm{day}^{-1}$, while the October-November av- 


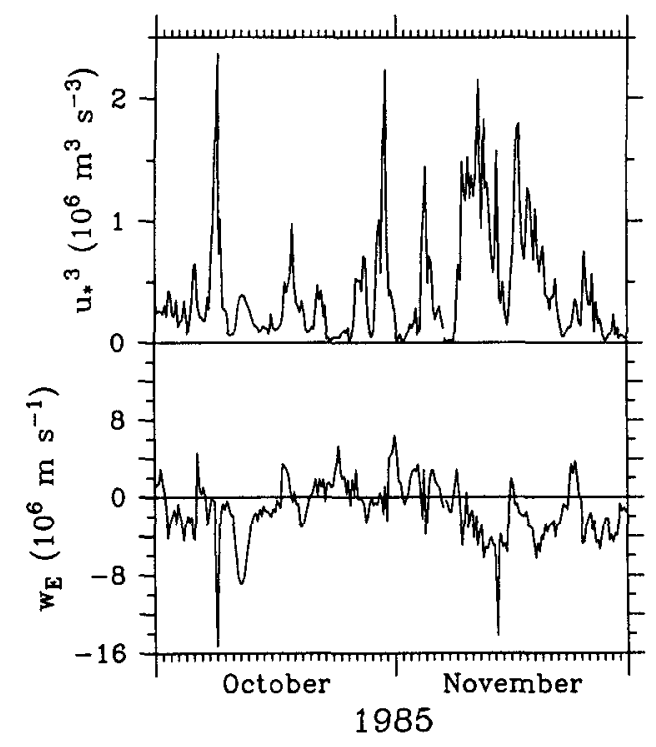

FIG. 15. Graphs of $u_{*}^{3}$ (top) and the vertical Ekman pumping velocity averaged over the subdomain between $26^{\circ}$ and $32^{\circ} \mathrm{N}$ east of $71^{\circ} \mathrm{W}$ (bottom).

erage outside of that period was $-0.1 \mathrm{~m} \mathrm{day}^{-1}$. Since FNOC winds underestimate the magnitude of fluctuations with wavelengths less than $1000 \mathrm{~km}$, these $w_{E}$ estimates are probably too small. Thus, Ekman pumping was favorable for aiding mixed layer entrainment just before and during the formation period, although its total significance cannot be established here.

\section{Summary and conclusions}

By analyzing a set of 5-day composite $T_{s}$ maps, we have documented the properties of westward-propagating $T_{s}$ anomalies in the western North Atlantic STCZ over a seven-year period. Although $T_{s}$ anomaly variability was energetic throughout the analysis domain, the features located between $26^{\circ}$ and $32^{\circ} \mathrm{N}$ had a strong tendency to propagate westward. East of about $71^{\circ} \mathrm{W}$, these features consistently propagated at 3-4 $\mathrm{km}$ day $^{-1}$ during all seven years. The propagation was strongly modified to the west of $71^{\circ} \mathrm{W}$ as the western boundary was approached. Propagation was only weakly evident during summer (June through September). The persistence of propagating features during the fall-spring intervals varied substantially from year to year but was always larger than during summer. The fall-spring features tended to anisotropic with variable major axis orientation. The characteristic wavelength of the features was $\sim 800 \mathrm{~km}$ in the minor axis direction and the characteristic period was $\sim 200$ days.

Cumulative evidence suggests that baroclinic eddies are ultimately responsible for the existence of the propagating anomaly features. Local stochastic atmospheric forcing is not capable of forcing anomalies with the observed magnitude, and this forcing mechanism cannot account for the westward propagation. Also, advection by mean currents cannot solely account for the westward propagation. Although predominantly westward mean flow is expected to exist in the Sargasso Sea based on simple subtropical gyre models, a zonal band of eastward mean current a few degrees of latitude wide apparently exists that separates regions of predominantly westward mean current. Dynamic topography maps presented in Stommel et al. (1978), Reid (1978), Ebbesmeyer and Taft (1979), and Olson et al. (1984) all reveal mean eastward current shear between the main thermocline and the surface in the central Sargasso Sea, while SOFAR floats deployed in the main thermocline near $700 \mathrm{~m}$ in the same region indicate that mean flow is eastward in the main thermocline (Rossby et al. 1983). Also, current moorings in the western North Atlantic at $28^{\circ} \mathrm{N}$ have consistently revealed eastward mean current in the upper ocean (Richman et al. 1977; Schmitz 1978; Brink 1989), although the statistical significance of mean currents obtained from individual mooring deployments is marginal. This eastward current may be analogous to the subtropical countercurrent observed in the western North Pacific (e.g., Uda and Hasunuma 1969). In contrast, the westward propagation speed of the anomalies is consistent with that expected for a first-mode baroclinic Rossby wave mode using a reasonable estimate of the radius of deformation. Large interannual variability occurs in some properties of the propagating anomalies, suggesting that interannual changes may be occuring in some properties of the eddy field. It will be important to investigate this possibility in the future. Such changes in properties might rationalize the observations of Schmitz $(1978,1989)$, who has documented substantial long-term variability in the statistical properties of eddy current variability, and hence in properties of the mesoscale eddy field, at the MODE site, which is contained within our analysis domain.

The propagating anomaly features are trapped within the STCZ between about $26^{\circ}$ and $32^{\circ} \mathrm{N}$. We could not find evidence in the literature of meridional variability in eddy properties that could be responsible for making eddy forcing more effective in the STCZ. In contrast, the zonal band between $26^{\circ}$ and $32^{\circ} \mathrm{N}$ contained the enhanced meridional $T_{s}$ gradients associated with the mean subtropical front, which makes anomaly forcing by horizontal eddy currents more effective. Unfortunately, we could not quantify the influence of horizontal eddy currents with available data. One event was observed where the influence of the eddy field on entrainment at the mixed-layer base could have been important. The strong anomaly features present during the 1985/86 fall-spring season appeared within a several-day interval near the beginning of November 1985. This coincided with the onset of relatively stormy fall weather when the first major mixed-layer deepening events probably occurred. Finally, the present study suggests that satellite-derived SST maps may be very useful in studying the mesoscale and large-scale influence of the underlying eddy field on the mixed-layer heat balance. 
Acknowledgments. This research was performed at the University of Rhode Island with the support of the Office of Naval Research (No. N00014-87-KT0235) as part of FASINEX. All figures were generated using the interactive graphics package PLOT5, developed by Dr. Donald Denbo. The work of one author (D. Byrne) was performed at URI as a Summer Undergraduate Research Fellow with support from the National Science Foundation under Grant OCE-8900626. The image processing software was developed by $R$. Evans, $O$. Brown, J. Brown, and A. Li at the University of Miami under Office of Naval Research funding. The continuing support of the Miami group is gratefully acknowledged.

\section{REFERENCES}

Brink, K. H., 1989: Evidence for wind-driven current fluctuations in the western North Atlantic. J. Geophys. Res., 94, 2029-2044.

Camp, N. T., and R. L. Elsberry, 1978: Oceanic thermal response to strong atmospheric forcing II: The role of one-dimensional processes. J. Phys. Oceanogr., 8, 215-224.

Carter, E. F., and A. R. Robinson, 1987: Analysis models for the estimation of oceanic fields. J. Atmos. Oceanic Technol., 4, 4974.

Dantzler, H. L., Jr., 1977: Potential energy maxima in the tropical and subtropical North Atlantic. J. Phys. Oceanogr., 7, 512-519.

Ebbesmeyer, C. C., and B. A. Taft, 1979: Variability of potential energy, dynamic height, and salinity in the main pycnocline of the western North Atlantic. J. Phys. Oceanogr., 9, 1073-1089.

Emery, W. J., 1983: On the geographical variability of the upper level mean and eddy fields in the North Atlantic and North Pacific. J. Phys. Oceanogr., 13, 269-291.

Frankignoul, C., 1981: Low-frequency temperature fluctuations off Bermuda. J. Geophys. Res., 86, 6522-6528.

- 1985 : Sea surface temperature anomalies, planetary waves, and air-sea feedback in the middle latitudes. Rev. Geophys., 23, 357-390.

plication to sea-surface temperature variability and thermocline variability. Tellus, 29, 284-305.

— mid-latitude sea-surface temperature anomalies. $J$. Phys. Oceanogr., 13, 1131-1145.

Halliwell, G. R., Jr., 1991: Ship-of-opportunity XBT cross-sections of the western North Atlantic subtropical convergence zone. $J$. Geophys. Res., in press.

—_, and —_, 1989: Large-scale SST anomalies associated with subtropical fronts in the western North Atlantic during FASINEX. J. Mar. Res., 47, 757-775.

_- , and —_, 1990a: Large-Scale SST Variability in the Western North Atlantic Subtropical Convergence Zone during FASINEX. Part I: Description of SST and wind stress fields. J. Phys. Oceanogr., 20, 209-222.

North Atlantic Subtropical Convergence Zone during FASINEX. Part II: Upper-ocean heat balance and frontogenesis. J. Phys. Oceanogr., 20, 223-234.

Hasselmann, K., 1976: Stochastic climate models. Part I. Theory. Tellus, 28, 473-485.

Kang, Y. Q., and L. Magaard, 1982: Annual temperature fluctuations at the subtropical and subarctic fronts in the central North Pacific. J. Geophys. Res., 87, 5663-5666.

Klein, P., and B. L. Hua, 1988: Mesoscale heterogeneity of the winddriven mixed layer: Influence of a quasi-geostrophic flow. $J$. Mar. Res., 46, 495-525.

Nelepo, B. A., Yu. M. Kuftarkov and V. K. Kosnyrev, 1978: Effects of mesoscale eddies on ocean surface temperature. Izv. Atmos. Oceanic Phys., 14, 545-550.

Olson, D. B., F. A. Schott, R. J. Zantopp and K. D. Leaman, 1984: The mean circulation east of the Bahamas as determined by a recent measurement program and historical XBT data. $J$. Phys. Oceanogr., 14, 1470-1487.

Pratt, R. W., 1976: The interpretation of space-time spectral quantities. J. Atmos. Sci., 33, 1060-1066.

Reid, J. L., 1978: On the middepth circulation and salinity field in the North Atlantic Ocean. J. Geophys. Res., 83, 5063-5067.

Reynolds, R. W., 1979: A stochastic forcing model of sea surface temperature anomalies in the North Pacific and North Atlantic. Tech. Rep. 8, Climate Research Institute, Oregon State University, Corvallis, Oregon.

Richman, J. G., C. Wunsch and N. G. Hogg, 1977: Space and time scales of mesoscale motion in the sea. Rev. Geophys. Space Phys., $15,385-420$.

Robinson, A. R., N. E. Huang, C. D. Leitao and C. G. Parra, 1983: A study of the variability of ocean currents in the northwestern Atlantic using satellite altimetry. $J$. Phys. Oceanogr., 13, 565585.

Roden, G. I., 1975: On North Pacific temperature, salinity, sound velocity, and density fronts and their relation to the wind and energy flux fields. J. Phys. Oceanogr., 5, 557-571.

Rossby, H. T., S. C. Riser and A. J. Mariano, 1983: The western North Atlantic-a la-grangian viewpoint. Eddies in Marine Science, A. R. Robinson, Ed., Springer-Verlag, 66-91.

Schmitz, W. J., Jr., 1978: Observations of the vertical distribution of low-frequency kinetic energy in the western North Atlantic. J. Mar. Res., 36, 295-310.

—, 1989: The MODE site revisited. J. Mar. Res., 47, 131-151.

Shapiro, R., 1970: Smoothing, filtering, and boundary effects. Rev. Geophys. Space Phys., 8, 359-387.

Shen, C. Y., J. C. McWilliams, B. A. Taft, C. C. Ebbesmeyer and E. J. Lindstrom, 1986: The mesoscale spatial structure and evolution of dynamical and scalar properties observed in the northwestern Atlantic Ocean during the POLYMODE Local Dynamics Experiment. J. Phys. Oceanogr., 16, 454-482.

Stage, S. A., and R. A. Weller, 1985: The Frontal Air-Sea Interaction Experiment (FASINEX). Part I: Background and scientific objectives. Bull. Amer. Meteor. Soc., 66, 1511-1520.

__ and - 1986: The Frontal Air-Sea Interaction Experiment (FASINEX). Part II: Experimental plan. Bull. Amer. Meteor. Soc., 67, 16-20.

Stevenson, J. W., 1983: The seasonal variation of the surface mixedlayer response to the vertical motion of linear Rossby waves. $J$. Phys. Oceanogr., 13, 1255-1268.

Stommel, H., P. Niiler and D. Anati, 1978: Dynamic topography and recirculation in the North Atlantic. J. Mar. Res., 36, 449468.

Sturges, W., and A. Summy, 1982: Low-frequency temperature fluctuations between ocean station Echo and Bermuda. J. Mar. Res., 40(Suppl.), 727-746.

Turner, J. S., and E. B. Kraus, 1967: A one-dimensional model of the seasonal thermocline. Part II: The general theory and its consequences. Tellus, 19, 98-105.

Uda, M., and K. Hasunuma, 1969: The eastward subtropical countercurrent in the western North Pacific Ocean, J. Oceanogr. Soc. Japan, 25, 201-210.

Van Woert, M. L., 1982: The subtropical front: satellite observations during FRONTS 80. J. Geophys. Res., 87, 9523-9536.

Voorhis, A. D., 1969: The horizontal extent and persistence of thermal fronts in the Sargasso Sea. Deep-Sea Res., 16(Suppl.), 331337.

— - E. H. Schroeder and A. Leetmaa, 1976: The influence of deep mesoscale eddies on surface temperature in the North Atlantic subtropical convergence. J. Phys. Oceanogr., 6, 953-961.

Willebrand, J., 1978: Temporal and spatial scales of the wind field over the North Pacific and North Atlantic. J. Phys. Oceanogr., 8, 1080-1094. 